Portland State University

PDXScholar

\title{
Connecting Chemistry to Community with Deliberative Democracy
}

\author{
Regis Komperda \\ Portland State University, regis.komperda@pdx.edu \\ Jack Barbera \\ Portland State University, jbarbera@pdx.edu \\ Erin Shortlidge \\ Portland State University, eshortlidge@pdx.edu \\ Gwen Shusterman \\ Portland State University
}

STEM Education and Equity Institute, Portland State University

Follow this and additional works at: https://pdxscholar.library.pdx.edu/bio_fac

Part of the Biology Commons, and the Chemistry Commons

Let us know how access to this document benefits you.

\section{Citation Details}

Komperda, R., Barbera, J., Shortlidge, E. E., \& Shusterman, G. P. (2018). Connecting Chemistry to Community with Deliberative Democracy. In Citizens First! Democracy, Social Responsibility and Chemistry (Vol. 1297, pp. 81-98): American Chemical Society. https://pubs.acs.org/doi/abs/10.1021/ bk-2018-1297.ch006

This Book Chapter is brought to you for free and open access. It has been accepted for inclusion in Biology Faculty Publications and Presentations by an authorized administrator of PDXScholar. Please contact us if we can make this document more accessible: pdxscholar@pdx.edu. 


\title{
Chapter 6
}

\section{Connecting Chemistry to Community with Deliberative Democracy}

\author{
Regis Komperda, ${ }^{1}$ Jack Barbera, ${ }^{1}$ Erin E. Shortlidge, ${ }^{2}$ \\ and Gwendolyn P. Shusterman 1,3," \\ 1Department of Chemistry, Portland State University, Portland, \\ Oregon 97207, United States \\ 2Department of Biology, Portland State University, Portland, Oregon 97207, \\ United States \\ ${ }_{3}^{3}$ TEM Education and Equity Institute, Portland State University, Portland, \\ Oregon 97207, United States \\ "E-mail: shusteg@pdx.edu
}

\begin{abstract}
Science education communities have called for rethinking curricula to improve student understanding of the nature of science and the role of science in addressing controversial modern issues such as climate change, energy policy, and pollution levels. One approach to meeting this call is integrating these topics into class activities that require students to use discussion and scientific approaches to solve problems and deliberate potential policy solutions. Deliberative democracy (DD) is one such active learning approach in which students work in peer groups to reach a consensus on a scientific topic relevant to both real-world issues and course content. During DD modules, students are asked to explore both the scientific data and public perception surrounding a topic by reading related peer-reviewed and media articles. Students evaluate the information provided by these sources, have the opportunity to research their own sources, deliberate in groups, and arrive at an evidence-supported position on a science policy. There are some examples in the literature of using DD in nonmajors science courses, and recently Portland State University (PSU) began incorporating DD modules into both on-sequence and off-sequence general chemistry courses for science majors enrolling between 60 and 200 students. This chapter provides
\end{abstract}

(C) 2018 American Chemical Society

Maguire and Sheardy; Citizens First! Democracy, Social Responsibility and Chemistry ACS Symposium Series; American Chemical Society: Washington, DC, 2018. 
background on DD, explains how DD has been adapted for majors-level general chemistry at PSU, highlights perceptions of DD by students and instructors, and describes how feedback from PSU students and instructors is informing future DD implementation at PSU.

\section{The Scientific Process and Deliberative Democracy}

The structure and content of the chemistry curriculum is a frequent topic of discussion in the chemistry education literature (1-6). One point raised in these discussions is whether chemistry should be taught as a collection of facts or as a way of thinking (7). A scientific way of thinking involves understanding the role of chemistry in decision-making regarding modern issues (7) as well as appreciating the dynamic nature of chemical knowledge (8). The concern that students view science as a static body of knowledge is not unique to chemistry and is echoed by other science educators who encourage more deliberate teaching of the nature of science as a social enterprise in which knowledge is constructed through debate and consensus building as new facts and evidence become available $(9,10)$. Activities have been developed to increase student understanding of the nature of science by engaging in discussions of issues with both social and scientific relevance, such as climate change and energy policy (11-13). Engaging in deliberation during these types of activities has been shown to teach science content along with scientific reasoning skills (13).

One specific method employed for this type of deliberation and consensus building exercise is deliberative democracy (DD), which comes from a tradition of deliberative practices used not only within higher education classrooms (14, $15)$, but also as a tool for conducting political discussions around government policies (16). The practice of deliberation "requires each person to think critically and creatively, listen attentively, examine assumptions, value differences, engage in respectful and honest dialogue, and reach well-reasoned judgments (15)" (p. 24). The consensus reached during DD is not a result of a single side winning a debate, but rather a thoughtful integration of all perspectives resulting in a conclusion supported by all stakeholders. Implementation of DD consensus building activities in science classrooms not only aligns with calls to improve science communication by addressing both the facts and the values individuals carry with them when engaging in decision-making (17), but also with calls to move science education away from traditional lectures and towards more student-centered teaching by providing students opportunities to actively engage in their own knowledge construction (18). In this way, DD activities can provide a parallel to the consensus building that defines the construction of scientific knowledge.

This chapter will provide examples of how DD has been implemented in undergraduate science courses for nonscience majors and describe how integrating DD into a redesigned nonmajors biology course at Portland State University (PSU) served as the catalyst for incorporating DD modules into majors-level science courses at PSU as part of an ongoing multi-year Howard Hughes Medical Institute 
(HHMI) funded project. The first year of DD implementation in PSU general chemistry courses will be detailed along with feedback from students and DD facilitators, lessons learned from this first implementation, and plans for future DD use at PSU.

\section{Deliberative Democracy in Science Courses}

Activities explicitly tied to the DD framework are beginning to appear in the science education literature (19-21). One of the first examples describes a DD module designed to improve understanding of nanotechnology by both the general public and chemistry students at the University of Wisconsin-Madison (19). The exercise was completed by four groups of participants including the university students and the general public, with median group ages ranging from 19 to 68. Combined, all participants showed an increase in their general nanoscience knowledge after the DD exercise based on responses to a 6-item pre- and post-test. The largest, and youngest, group in the study consisted of 55 students (43 female) of the 200 students enrolled in an introductory chemistry laboratory course for nonscience majors. The students were assigned a specific area of nanotechnology to research using a website created for the project. Deliberation was completed in groups of $\sim 20$ students in a single 1.5 -hour session led by a facilitator where students presented risks and benefits for their specific area and reached a consensus on how to allocate a hypothetical research budget. In addition to their increased nanoscience knowledge, the students increased their interest in and support of nanotechnology.

Another implementation of DD in a nonscience majors chemistry course was undertaken with 52 students at the all-male Wabash College (20). The DD activity comprised three 50-minute class periods with the first class devoted to a lecture connecting energy policy to content covered earlier in the course. Students were assigned to read materials on energy policy developed for the general public. With the help of a trained facilitator, either a faculty member or a student learning assistant, students spent the second and third class periods in groups of $\sim 8$ students discussing the three possible energy policy approaches described in the reading materials. At the end of the third day, each group reported their conclusions to the class. Similar to the nanotechnology study, pre- and post-activity surveys were used to examine changes in content knowledge as well as students' perception of connections between topics studied in chemistry and real-world issues. After the DD activity, students showed increased content knowledge related to energy and also felt that they better understood the role of chemistry in addressing real-world issues. Additionally, when asked at the end of the course to identify interesting or useful things learned in the course over half of the students mentioned the DD activity or energy policy.

\section{Starting Deliberative Democracy at PSU}

Both of the previous examples were conducted as single DD exercises integrated into chemistry courses for nonscience majors. At PSU, the DD model 
was first used to transform a large enrollment ( 200 students) introductory biology course for nonscience majors (21). Unlike the previous examples, the entire course was restructured around DD. Lecture time was reduced and four DD modules were integrated into the 10 -week course, including a first introductory module to familiarize students with the scientific method and the DD process. The DD topics were tied to ongoing policy debates including regulating sizes of sugar-sweetened drinks, at-home genetic testing kits, and genetically modified foods.

Another key difference from the previous DD examples is that, rather than being given a pre-determined set of materials to read for information on a topic, in this course students were expected to search on their own for relevant information to support their group's deliberation (21). In-class activities were developed to support students in learning to read and evaluate the validity of sources of scientific information, such as those found in both popular media and peer-reviewed literature. These in-class activities were done as interactive or group activities on days where lectures on course content were also given.

The DD modules in this introductory biology class lasted for five class periods with the bulk of the in-class DD work being completed in groups of $\sim 9$ students on the first and fifth class periods (21). The intervening days were for the lectures and scientific reading activities described previously. The first day of a module was used to introduce the topic, assign roles within the group, report an initial stance on the policy issue, determine what additional information was needed to address the policy, and assign responsibility for gathering the information to specific students. On the final day of the module, students brought in their outside information, held group discussions, and arrived at a consensus on the policy issue. The course instructor was the only facilitator in the room and spent the final day of each module moving between groups and occasionally engaging the whole class in conversation about specific issues or questions raised by groups.

The effect of the redesigned course on student learning was evaluated by measuring changes in students' content knowledge and self-reported understanding of biology content (21). Students' content knowledge increased both for topics covered in lecture as well as topics covered in the media articles assigned to students in each DD module, with larger gains for topics covered in the media articles. Students also reported an increased understanding of biology content covered in class relative to topics not covered in class. In addition to content knowledge, students were also found to be developing skills related to engaging with scientific literature and policies based on science. Students were reported to be utilizing a variety of sources in their deliberations as well as examining their sources for validity and credibility. When reflecting on the DD modules, students felt more comfortable turning to the scientific literature to inform their personal choices as well as policy decisions.

These outcomes demonstrated that DD was an effective strategy for teaching not only content knowledge, but also for engaging PSU students in real-world social and policy issues. The success of this DD model in a large-enrollment course catalyzed the development of a HHMI-funded project to bring DD to large-enrollment majors-level biology, chemistry, and physics courses at PSU. The goals of the current project emphasized increasing student engagement with 
course material, their peers, and the scientific literature as well as to impact students' science identity and their perceptions of the role of science in their lives in the context of connecting chemistry course content to real-world issues. The first year of DD implementation in PSU general chemistry courses is the focus of the remainder of this chapter.

\section{Deliberative Democracy in General Chemistry at PSU}

Portland State University (PSU) is an urban public university comprised of over 25,000 undergraduate students, as of Fall 2017 (22). A majority of the PSU student population is from Oregon (78\%) and attends school full time (60\%) (22). Though the racial makeup of PSU students is majority white (56\%), PSU serves a nontraditional population of undergraduates with an average age of 26 (23). The academic year at PSU is comprised of three 10-week quarters.

The year-long general chemistry course sequence at PSU is offered both onsequence with General Chemistry I starting in the fall term and also off-sequence with General Chemistry III offered in the fall term. On-sequence general chemistry is taught in sections of 150-400 students in a newly built lecture hall with seats that can swivel to facilitate group work and large spaces between rows of seats which allow a facilitator to easily move throughout the room. The off-sequence course has a typical enrollment of $60-100$ students and is taught in a traditional lecture hall with fixed seats and limited ability for an instructor to move throughout the room. Prior to the implementation of DD in the general chemistry courses, on-sequence general chemistry was conducted using a process oriented guided inquiry learning (POGIL) format (24) with students working in small groups during class while the off-sequence course used a lecture format. All courses used the same textbook (25).

\section{Module Development and Implementation}

A summer workshop was held in 2015 in preparation for the implementation of DD in large-enrollment majors-level biology, chemistry, and physics courses at PSU. Faculty and graduate students from each department attended the workshops to learn more about DD and how it had been implemented in the nonmajors biology course at PSU (21). The faculty attending the workshop brainstormed potential DD topics that would fit with content for the course they would be teaching in the upcoming academic year. After the workshop, graduate students worked together to develop DD materials for courses in their respective disciplines, under the direction of the faculty teaching the courses in which DD was to be implemented. The graduate students were responsible for developing the modules by finding appropriate articles and creating student materials including worksheets and article quizzes. The module topics and articles selected for general chemistry classes in the first year of DD implementation are provided in Table 1. Both faculty and graduate students received a stipend for their time. 
Each faculty member had complete autonomy regarding the decision of whether and how to implement DD within his or her own course. As a result, each of the four general chemistry implementations followed a slightly different format based on the preferences of the instructor. Table 2 provides information on how each instructor chose to integrate DD into each course.

Though each instructor used a different format, core components occurred in every implementation. These included a preliminary introduction to DD in which the purpose of DD was described as an opportunity for students to connect their knowledge of course content with a real-life policy issue. Other common components were the two stages of deliberation: the first to arrive at an initial policy statement based only on current knowledge of a topic, and the second deliberation to arrive at a final consensus statement based on information obtained from reading the assigned media and peer-reviewed articles, as well as the external information obtained by the students. These deliberation sessions were facilitated either solely by the course instructor or in some cases, described more fully in the following sections, with assistance from a graduate teaching assistant (GTA) or undergraduate learning assistants (LAs).

Regardless of who was facilitating, facilitation involved stopping to talk to each group about their findings and encouraging students to consider aspects of the issue they had potentially not yet identified. The facilitation process during deliberations closely mirrored the process used in the article describing the first implementation of DD in nonmajors biology at PSU (21). In the preliminary deliberation students identified the additional information they needed to make a decision and assigned responsibility for obtaining this information to a group member. On the final deliberation day students recorded the evidence they used to support their final consensus statement as well as the source of the evidence. Students were instructed that arrival at this final consensus needed to be the result of full agreement between all group members on a recommended course of action that was not the result of opinions, but supported by the literature they had read.

The general chemistry course instructors decided to implement a single DD module each term, starting with the off-sequence General Chemistry III in fall 2015, followed by on-sequence General Chemistry II in winter 2016, on-sequence General Chemistry III in spring 2016, and off-sequence General Chemistry III again in fall 2016. All general chemistry courses implementing DD met for 65minute periods three days per week. The same instructor, Instructor A, taught the fall 2015 and fall 2016 courses with assistance from a co-instructor for the DD activity (Guest instructor A). Different instructors taught in winter 2016 and spring 2016 (Instructor B and Instructor C, respectively). The lead graduate teaching assistant (GTA) was the same for the entire 2015-2016 academic year and, for some terms, an additional GTA as well as undergraduate learning assistants (LAs) assisted with group facilitation. 
Table 1. Description of courses with deliberative democracy (DD) implementation fall 2015 through fall 2016.

\begin{tabular}{|c|c|c|c|c|}
\hline Term & Fall 2015 & Winter 2016 & Spring 2016 & Fall 2016 \\
\hline Course & General Chemistry III & General Chemistry II & General Chemistry III & General Chemistry III \\
\hline Facilitator & $\begin{array}{l}\text { Instructor A, guest instructor } \\
\mathrm{A} \text {, and two GTAs }\end{array}$ & $\begin{array}{l}\text { Instructor B, lead } \\
\text { GTA, and LAs }\end{array}$ & $\begin{array}{l}\text { Instructor C, lead } \\
\text { GTA, and LAs }\end{array}$ & $\begin{array}{l}\text { Instructor A and guest } \\
\text { instructor A }\end{array}$ \\
\hline Course Format & Primarily lecture & Primarily POGIL & Primarily POGIL & Primarily lecture \\
\hline DD Topic & $\begin{array}{l}\text { Funding allocation for } \\
\text { infectious disease } \\
\text { eradication }\end{array}$ & $\begin{array}{l}\text { Limiting } \mathrm{CO}_{2} \\
\text { emissions }\end{array}$ & $\begin{array}{l}\text { Monitoring local glass } \\
\text { company emitting } \\
\text { chromium }\end{array}$ & $\begin{array}{l}\text { Funding allocation for } \\
\text { infectious disease } \\
\text { eradication }\end{array}$ \\
\hline $\begin{array}{l}\text { Related Course } \\
\text { Content }\end{array}$ & Acid-base chemistry & Equilibrium & $\begin{array}{l}\text { Oxidation-reduction } \\
\text { reactions }\end{array}$ & $\begin{array}{l}\text { Acid-base chemistry and } \\
\text { organic line drawings }\end{array}$ \\
\hline Media Article & $\begin{array}{l}\text { From Aspiration to Action: } \\
\text { What Will it Take to End } \\
\text { Malaria? }\end{array}$ & $\begin{array}{l}\text { Short Answers to Hard } \\
\text { Questions about } \\
\text { Climate Change }^{27}\end{array}$ & $\begin{array}{l}\text { How Lead Ended up in } \\
\text { Flint's Tap Water }{ }^{28}\end{array}$ & $\begin{array}{l}\text { Hard Times in Venezuela } \\
\text { Breed Malaria as Desperate } \\
\text { Flock to Mines }{ }^{29}\end{array}$ \\
\hline $\begin{array}{l}\text { Peer-reviewed } \\
\text { Article }\end{array}$ & $\begin{array}{l}\text { Synthesis, Structure-Activity } \\
\text { Relationship, and Mode-of- } \\
\text { action Studies of } \\
\text { Antimalarial Reversed } \\
\text { Chloroquine Compounds }{ }^{30}\end{array}$ & $\begin{array}{l}\text { Saturation-state } \\
\text { Sensitivity of Marine } \\
\text { Bivalve Larvae to } \\
\text { Ocean Acidification }\end{array}$ & $\begin{array}{l}\text { Lead Contamination of } \\
\text { Potable Water due to } \\
\text { Nitrification }^{32}\end{array}$ & $\begin{array}{l}\text { Synthesis, Structure- } \\
\text { Activity Relationship, and } \\
\text { Mode-of-action Studies of } \\
\text { Antimalarial Reversed } \\
\text { Chloroquine Compounds }{ }^{30}\end{array}$ \\
\hline
\end{tabular}


Table 2. Use of class time spent during deliberative democracy (DD) activities with core DD components shaded

\begin{tabular}{|c|c|c|c|c|}
\hline & Fall 2015 & Winter 2016 & Spring 2016 & Fall 2016 \\
\hline \multirow[b]{2}{*}{ Class 1} & \multirow{2}{*}{$\begin{array}{l}\sim 20 \text { min: Regular class } \\
\sim 40 \text { min: Introduction to } \\
\text { DD topic and reading peer- } \\
\text { reviewed article }\end{array}$} & 230 min: Regular class & $\begin{array}{l}\sim 20 \text { min: Instruction on } \\
\text { content related to DD topic }\end{array}$ & \multirow{2}{*}{$\begin{array}{l}\sim 30 \text { min: Regular class } \\
\sim 30 \text { min: Introduction to DD } \\
\text { topic and reading peer- } \\
\text { reviewed article }\end{array}$} \\
\hline & & $\begin{array}{l}\sim 30 \text { min: Introduction to } \\
\text { DD process, group } \\
\text { formation and initial stance }\end{array}$ & $\begin{array}{l}\sim 45 \text { min: Introduction to } \\
\text { DD process, group } \\
\text { formation and initial stance }\end{array}$ & \\
\hline \multirow{2}{*}{ Class 2} & $\begin{array}{l}\sim 15 \text { min: Introduction to } \\
\text { DD process, group } \\
\text { formation and initial stance }\end{array}$ & \multirow{2}{*}{$\begin{array}{l}\sim 15 \text { min: Instruction on } \\
\text { content related to DD topic } \\
\sim 50 \text { min: Regular class }\end{array}$} & \multirow{2}{*}{ Regular class } & $\begin{array}{l}\sim 30 \text { min: Introduction to DD } \\
\text { process, group formation and } \\
\text { initial stance }\end{array}$ \\
\hline & $\sim 50$ min: Regular class & & & $\begin{array}{l}\sim 35 \text { min: Group work on } \\
\text { content related to DD topic }\end{array}$ \\
\hline Class 3 & Regular class & Regular class & Regular class & $\begin{array}{l}\text { Group work on peer- } \\
\text { reviewed article and content } \\
\text { related to DD topic }\end{array}$ \\
\hline Class 4 & $\begin{array}{l}\sim 20 \text { min: Group work on } \\
\text { peer- reviewed article } \\
\sim 45 \text { min: Regular class }\end{array}$ & $\begin{array}{l}\text { Group deliberation and } \\
\text { consensus }\end{array}$ & $\begin{array}{l}\text { Group deliberation and } \\
\text { consensus }\end{array}$ & $\begin{array}{l}\text { Group deliberation and } \\
\text { consensus }\end{array}$ \\
\hline Class 5 & $\begin{array}{l}\text { Group deliberation and } \\
\text { consensus }\end{array}$ & Regular class activities & Regular class activities & $\begin{array}{l}\sim 20 \text { min: DD topic wrap-up } \\
\text { organic line drawings } \\
\sim 45 \text { min: Regular class }\end{array}$ \\
\hline Class 6 & $\begin{array}{l}\sim 20 \mathrm{~min}: \text { DD topic wrap-up } \\
\sim 45 \text { min: Regular class }\end{array}$ & Regular class activities & Regular class activities & Regular class activities \\
\hline
\end{tabular}




\section{$\underline{\text { DD Topic }}$}

The policy topic chosen by Instructor A was allocation of funding for eradication of infectious diseases, which was based on Instructor A's research on malaria drugs. A publication of this research was used as the peer-reviewed article (30). The media article used in fall 2015 was a joint report from the Bill \& Melinda Gates Foundation and the United Nations (26). This module was refined and used again in the fall of 2016 and the media article was replaced with a New York Times article on malaria in Venezuela (29). The DD module was connected to acid-base chemistry by having students consider the structural factors necessary for effective drug delivery.

\section{DD Activity Structure}

The structure of the DD module in the off-sequence course was similar to the structure used in the nonmajors introductory biology course (21). The module activities spanned six class periods in 2015 and five class periods in 2016. The timing of the activities is shown in Table 2. In the first class where DD was introduced, the final $\sim 40$ minutes of the period were devoted to an explanation of the purpose of DD and a brief introduction to the policy topic to be discussed, infectious diseases. Additionally, during this time Instructor A provided some basic information on how to read a peer-reviewed scientific article. Students spent the first $\sim 15$ minutes of the following class period establishing groups of $\sim 6$ students, assigning roles, forming an initial stance on the policy topic, and determining what additional information needed to be gathered to address the policy topic. The rest of that class period and the following class period consisted of regular class instruction, unrelated to DD. During the fourth class, students spent $\sim 20$ minutes working together on guided questions helping them understand the peer-reviewed article. The full 65 minutes of the fifth class were used for the group deliberation and consensus on how funding should be allocated for infectious disease eradication. The group work on the peer-reviewed article and the final deliberation day were facilitated by the guest instructor, the lead GTA, and an additional GTA. Instructor A used the first $\sim 20$ minutes of the next class to wrap up the topic before returning to regular class instruction.

As seen in Table 2, when the module was used again in fall 2016 most of the structure of the DD activity remained the same, but the overall length of the DD implementation was shortened by removing the class periods spent on instruction of content unrelated to the DD activity. Instead, a new activity was developed to reinforce acid-base concepts, improve student capability to identify organic acidbase pairs, and teach organic chemistry line drawings so that students could better understand the structures of the drugs they were reading about. These topics were briefly introduced by the guest instructor with most of the in-class time spent with students working in groups on POGIL-type worksheets. 


\section{$\underline{\text { DD Topic }}$}

For on-sequence General Chemistry II in winter 2016, Instructor B chose a policy topic concerning carbon dioxide emissions. Carbon dioxide emissions were chosen to tie into the equilibrium chemistry taught during that term. To reinforce the connection to both course content and local issues, Instructor B chose a peerreviewed article related to the chemistry of dissolved carbon dioxide and its effects on marine organisms in Oregon (31). The media article accompanying this module appeared in the New York Times (27) and provided information on climate change, including the role of carbon dioxide emissions.

\section{$\underline{\text { DD Activity Structure }}$}

The structure of the DD module in winter 2016 contained the same core components as the fall module: a partial class period spent introducing DD, forming groups of $\sim 6$ students, stating an initial stance and identifying additional information needed to address the policy issue followed by a full class period in which the groups deliberated and arrived at a consensus. These core DD components are highlighted in Table 2. Due to the larger enrollment for this on-sequence course, undergraduate learning assistants (LAs) attended the final deliberation day to help facilitate group discussions. Similar to the fall 2015 implementation, the class periods between the initial group formation and final deliberation were spent on regular class instruction that was not directly tied to the DD topic. Another difference in this module was that students read both the media and peer reviewed articles on their own outside of class and answered quiz questions on the readings online.

\section{On-Sequence General Chemistry III}

\section{$\underline{\text { DD Topic }}$}

The DD module used in the on-sequence General Chemistry III course in spring 2016 was based around a local issue, the emission of chromium from a glass manufacturing plant near downtown Portland, Oregon. This topic was tied to the oxidization-reduction content covered in the third term course. Both the media and peer-revised articles read by students addressed related aspects of environmental contamination: lead contamination of water due to changes in $\mathrm{pH}$. The media article from Chemical and Engineering News reported on the national story of the Flint water crisis (28) while the peer-reviewed article described experimental conditions found to affect lead solubility (32). 


\section{DD Activity Structure}

The format of the DD module in spring 2016 was similar to the on-sequence winter 2016 course where article readings were done outside of class and the in-class group work was facilitated by the instructor, the lead GTA, and LAs. As before, the core components of the DD module remained the same with a partial class period spent on introduction to DD, initial group formation, and initial stance development. The two subsequent class periods were spent on regular class instruction followed by a final full class period of group deliberation and arrival at a consensus on how to address the issue.

\section{Evaluation}

As part of the larger HHMI-funded project, the implementation of DD modules in all large-enrollment science courses is being evaluated from a variety of perspectives including both the students enrolled in the courses and the instructors and GTAs involved in developing and facilitating the DD modules in class. The evaluations of DD described in this chapter are related to student and facilitator (instructor and GTA) perceptions of the DD modules that informed refinement of the DD modules prior to implementation in the 2017-2018 academic year. As the project continues, future publications will describe various outcomes measured as part of this ongoing project evaluation.

\section{Students}

Student perceptions of DD were solicited on an end-of term survey given in all three General Chemistry III courses in fall 2015, spring 2016, and fall 2016. The students in General Chemistry II were not surveyed. At the end of the survey, students were asked to respond to open-ended items targeting which aspects of the course influenced their interest in or learning of chemistry and were invited to give specific feedback on the DD modules. Only 9 of the 72 (13\%) fall 2015 students provided responses to the DD-specific open-ended survey question, though this improved to 28 out of $60(47 \%)$ in fall 2016 and 95 out of $138(69 \%)$ in spring 2016. For this reason, the responses may not be generalizable to all students in the course, but they do provide some insight into student perceptions of DD.

\section{Student Perceptions of the Infectious Disease Module}

Students in the fall 2015 and fall 2016 off-sequence General Chemistry III courses who participated in the DD module on infectious diseases were less likely to respond to the open-ended survey questions, but of those who did respond, at least half (21 of 37 ) had positive comments on the DD module. These positive comments could be classified into general themes, including: finding the module topic interesting, generally due to connecting course content to real life (13 responses), or more specifically enjoying learning about the research conducted 
by their course instructor ( 2 responses), while others enjoyed the group work aspect ( 5 responses). Fully negative comments from students in these courses were limited (7 responses), but focused on feeling as though the DD module was a waste of class time because it did not relate directly to course content. A similar proportion of comments contained both positive and negative statements (5 responses) echoing the previous themes of appreciating the real-life connections but worrying about wasting class time. Students describing DD as a waste of class time indicated a preference for spending more time solving problems that would be on exams. A selection of representative student quotes for these themes from the off-sequence General Chemistry III course are given below with information indicating the theme and year of the response.

"The Deliberative Democracy section was an excellent use of class time and really got my interest in science engaged as it demonstrated how science and policy combine to enact change." [connection to real life Fall 2015]

"Deliberative Democracy was awesome. I got to dig into research on a specific disease and I got to learn about the process that scientists go through to get funded. This should have happened years ago...I wish for more Deliberative Democracy work in science classes. It really motivated me to work harder and helped me connect the dots." [connection to real life - Fall 2015]

"This was a good idea to implement, I learned that science is not only done in a lab. It is sometimes taken to the government to help decide policy." [connection to real life - Fall 2016]

"The Deliberative Democracy project was interesting way to learn while thinking outside of the box, and I hope that you continue to offer this option for [General Chemistry III]. I thought this was a really interesting project that allowed us to think critically using real world applications of chemistry. Even though I'm somewhat shy, it was an interesting project, and it encouraged group work that didn't lead to much anxiety." [connection to real life / group work - Fall 2016]

"Interesting to see real life applications but overall much too long and takes away from time that could be used to work on the already difficult material. If even one of the three classes were dedicated to practicing calculations I would feel much better." [connection to real life / waste of class time - Fall 2016]

\section{Student Perceptions of the Factory Emissions Module}

The 95 responses from the spring 2016 on-sequence General Chemistry III students had similar themes with students almost equally divided between positive 
(37 responses), negative (29 responses), and neutral (28 responses) perceptions of DD. As with the infectious disease module, the positive comments centered around finding the DD module interesting (8 responses) or more specifically described making connections between the course content and the real world (11 responses), though some students simply described generic positive feelings towards DD (12 responses). The negative comments described feeling as though the module was a waste of class time (11 responses) a lack of organization in the DD module (2) while others expressed a general dislike for DD (12 responses). A selection of representative student quotes from this on-sequence General Chemistry III course are given below.

"Great way to apply lessons learned in the term to real-world problems. Applying the science to real world problems in the DD exercises has increased my interest into science." [connection to real life - Spring 2016]

"It was hard to find articles on chromium in particular, but the research on the toxicity of heavy metals was interesting. The articles about nitrification and the water issues in Flint was a really good way to apply the things we'd been learning in class and it made me more interested in the subject matter and science in general. " [interesting - Spring 2016]

\section{“Worthless. Interesting material, but dislike the DD." [dislike - Spring 2016]}

"I personally think that the DDs aren't very helpful or beneficial. I would rather spend more time learning the material in class, and those points maybe could've been directed through assignments online." [waste of time - Spring 2016]

The positive student feedback indicated that some of the goals of DD were being met, especially those related to helping students see connections between content covered in class and real-world policy issues. The negative student feedback was likely due to the combination of the newness of the DD approach for both the facilitators and students at the time of these implementations as well as the fact that the single DD module format gave students less time to become familiar with what was expected of them. This student feedback points to the need to clearly define expectations for students and provide a clear structure to the DD modules.

\section{Facilitators}

Instructor and GTA perceptions of DD after the first year of implementation were obtained from interviews conducted by project staff after the term had ended. Some of the same themes from the student responses were found in the facilitator responses as well. Specifically, the course instructors worried about giving up 
class time to the DD modules and wanted to be sure that students were seeing the relevance of the DD module to course content. These types of student comments are what drove revisions to the DD module on infectious diseases to include a mini-lesson on organic line drawings and acid-base chemistry to more closely tie the structures in the peer-reviewed articles to the course content on organic acid structures. For the DD module on equilibrium, used in winter 2016, Instructor B specifically noted that the peer-reviewed article may have been too difficult for students and therefore it was harder for students to connect it to course content.

"I chose a research article that was all about equilibrium...it was about how $\mathrm{CO}_{2}$ dissolves in the ocean and changes the $\mathrm{pH}$ of the ocean and can destroy shellfish, specifically off the Oregon coast, which I'd though they would find really interesting...I think most of them kind of missed that piece... most of them didn't get that [exam] question right even though we went through it in class...none of their discussions centered on that paper. I think a lot of them found it, you know, sort of unreadable and they just basically answered the questions they needed to on the quiz and moved on. So it wasn't a good choice."

However, in spring 2016 during the DD module covering oxidation-reduction reactions the lead GTA felt that students were making connections between the chromium released by the glass factory and course content, "they [students] were talking about using reducing agents in the smoke columns/smoke stacks and how to reduce chromium six or chromium three."

Another parallel to the student feedback is that one of the instructors also found the DD activities activated connections between science and policy making.

"It made clearer why I care so much about politics now that I'm fully immersed as a scientist. Those sorts of links became crystallized... I get some opportunity to broach that topic in the classroom. Like how important it is to be scientifically literate, to be able to use literature to make up your mind is something I care about that just teaching by the book doesn't allow you to really approach. I do like the opportunity to glance[sic] politics. That's important to me and I think it should be important to them [students]..."

In considering scientific literacy and helping students learn to read scientific articles, the facilitators noted a need to spend more time helping students learn to read scientific literature and evaluate the validity of sources. In the on-sequence courses this had primarily been relegated to out-of-class activities done individually by students rather than as part of an in-class discussion as was done when DD was implemented in the nonmajors biology and the off-sequence General Chemistry III.

A final aspect brought up by all facilitators were the difficulties associated with implementing the DD modules for the first time without the benefit of being able to see implementation in another class. This was particularly a problem in the onsequence courses where LAs were available to facilitate the in-class deliberations 
but had no training in how to effectively facilitate groups since the entire DD approach was new to everyone involved. It is likely that these initial "blind" implementations led to some of the student feedback regarding disorganization and unclear expectations. As DD becomes a more regular part of these courses and implementations become more standardized, some of these issues should be minimized.

\section{Lessons Learned and Future Directions}

Feedback from both students and facilitators in the first year of DD use at PSU was important for understanding the strengths and weaknesses of various aspects of the implementation in general chemistry. This preliminary feedback indicates that the DD modules are engaging students in science in a way that is new and different to them and more in line with how their instructors experience science. Students are making connections between course content and their realworld experiences, reading scientific literature, and discussing the role of science in policy decisions.

In addition to this positive feedback, it was clear that all stakeholders-students, LAs, GTAs, and faculty-wanted a better understanding of what the implementation of a DD module should look like and what the expectations were for students. This more detailed understanding of DD has been a topic of discussion in informal community of practice meetings with the faculty and graduate students from all departments involved in DD development, implementation, and evaluation. Community of practice meetings have been held periodically throughout the academic year and helped identify the core components of DD while also providing an opportunity for sharing lessons learned from implementing DD and discussing ways to improve DD moving forward. The community of practice meetings have facilitated discussions of ways to standardize DD implementation across courses while still providing flexibility for instructors to incorporate DD in a way that best meets the needs of their course and students. This consistency is anticipated to be beneficial for students enrolled in multiple courses using DD throughout their time at PSU and has resulted in the development of a standardized set of worksheets for students to use to record their initial stances, external information sources, and eventual consensus statements.

Another theme in the feedback from both students and instructors is the tension between class time spent teaching science content and time spent addressing other aspects of science such as scientific thinking, science communication, and the role of science in society. For students and instructors to feel comfortable with DD and feel that DD has been a worthwhile part of the course, it is important to have clearly defined goals for DD and a way to assess if those goals are being met. We are currently working on developing a set of DD implementation materials that will articulate these goals for instructors and students while also providing a set of best practices derived from our evaluation of DD implementation across multiple science courses at PSU. These materials include a guide to help students navigate reading a scientific article, information 
on how to select valid scientific sources, and facilitation worksheets for each DD module that can be used by the course instructor, GTA, and LAs. These facilitation worksheets describe the course content students should be connecting to the DD module and provide ideas for probing questions facilitators can ask to foster student deliberation. At the conclusion of this HHMI-funded project we anticipate making a library of resources publically available including these implementation materials as well as sets of modules from which biology, chemistry, and physics instructors can select those that best fits the structure and content of their course. Currently, the facilitation worksheet for the infectious diseases DD module, a sample student worksheet, and general DD implementation guidelines are available for download (33). Examples of additional chemistry modules in development and their associated course content are listed in Table 3.

Table 3. General chemistry deliberative democracy modules undergoing development and testing

\begin{tabular}{|l|l|}
\hline Related Course Content & Deliberative Democracy Topic \\
\hline Measurement & Air quality monitoring \\
\hline Combustion & Carbon dioxide sources and emission levels \\
\hline Electromagnetic spectrum & Oxybenzone in sunscreen \\
\hline $\begin{array}{l}\text { Kinetics, equilibrium, } \\
\text { thermochemistry, and gases }\end{array}$ & Carbon capture \\
\hline Molecular structure and scale & Nanosilver as an antibacterial agent \\
\hline Solution chemistry & Desalination as source of fresh water \\
\hline Acid-base chemistry & Funding for infectious diseases \\
\hline Oxidation and reduction & Glass factory emissions and chromium levels \\
\hline $\begin{array}{l}\text { Oxidation and reduction and } \\
\text { solubility }\end{array}$ & Roadside drug testing \\
\hline
\end{tabular}

Though we are continuing to refine our approach to implementing DD and have not yet fully completed our analyses, preliminary results indicate that DD has helped align our general chemistry courses with calls to better integrate teaching course content with teaching the nature of science and the relationship between science and society $(7,9,10)$. During DD activities students are engaging in active learning with their peers and are gaining a better understanding of how science informs real-world policy decisions. We look forward to continuing to investigate the use of DD in science courses at PSU and hope that by sharing our experiences other science instructors consider using DD with their own students. 


\section{Acknowledgments}

This work was supported by an award to Portland State University under the Howard Hughes Medical Institute Science Education Program, Award \#52008105. We also gratefully acknowledge the contributions of the numerous faculty and graduate students who assisted with module development, classroom implementation, and project evaluation.

\section{References}

1. Spencer, J. N. J. Chem. Educ. 1992, 69, 182-186.

2. Lafarge, D. L.; Morge, L. M.; Méheut, M. M. J. Chem. Educ. 2014, 91, 173-178.

3. Kennedy, C. J. Chem. Educ. 2014, 91, 1280-1283.

4. Flynn, A. B.; Ogilvie, W. W. J. Chem. Educ. 2015, 92, 803-810.

5. Bruck, A. D.; Towns, M. J. Chem. Educ. 2013, 90, 685-693.

6. Schaller, C. P.; Graham, K. J.; Johnson, B. J.; Fazal, M. A.; Jones, T. N.; McIntee, E. J.; Jakubowski, H. V. J. Chem. Educ. 2014, 91, 321-328.

7. Talanquer, V.; Pollard, J. Chem. Educ. Res. Pract. 2010, 11, 74-83.

8. Shultz, G. V.; Gere, A. R. J. Chem. Educ. 2015, 92, 1325-1329.

9. Osborne, J. Science 2010, 328, 463-466.

10. Kolstoe, S. D. Int. J. Sci. Educ. 2000, 22, 645-664.

11. Khishfe, R.; Lederman, N. J. Res. Sci. Teach. 2006, 43, 395-418.

12. Sadler, T. D.; Barab, S. A.; Scott, B. Res. Sci. Educ. 2007, 37, 371-391.

13. Felton, M.; Garcia-Mila, M.; Gilabert, S. Informal Log. 2009, 29, 417-446.

14. Drury, S. A. M. In Deliberative pedagogy: Teaching and learning for democratic engagement; Shaffer, T., Longo, N. V, Manosevitch, I., Thomas, M. S., Eds.; Michigan State University Press: East Lansing, MI, 2017; pp 79-85.

15. Doherty, J. Connections; 2012; pp 24-27.

16. Einsiedel, E. F.; Eastlick, D. L. Sci. Commun. 2000, 21, 323-343.

17. Dietz, T. Proc. Natl. Acad. Sci. 2013, 110 (Suppl. 3), 14081-14087.

18. Freeman, S.; Eddy, S. L.; McDonough, M.; Smith, M. K.; Okoroafor, N.; Jordt, H.; Wenderoth, M. P. Proc. Natl. Acad. Sci. U. S. A. 2014, 111, $8410-8415$.

19. Jones, A. R.; Anderson, A. A.; Yeo, S. K.; Greenberg, A. E.; Brossard, D.; Moore, J. W. J. Chem. Educ. 2014, 91, 179-187.

20. Drury, S. A. M.; Stucker, K.; Douglas, A.; Rush, R. A.; Novak, W. R. P.; Wysocki, L. M. J. Chem. Educ. 2016, 93, 1879-1885.

21. Weasel, L. H.; Finkel, L. J. Coll. Sci. Teach. 2016, 45, 38-45.

22. Snapshot of Portland State. https://www.pdx.edu/profile/snapshot-portlandstate (accessed March 17, 2018).

23. Office of Institutional Research and Planning. Student Profile. http:// tableau.services.pdx.edu/Students/Student Profile.html (accessed March 17, 2018). 
24. Hanson, D. M. Foundations of chemistry: Applying POGIL principles, 4th ed.; Pacific Crest: Lisle, IL, 2010.

25. Tro, N. J. Chemistry: A molecular approach, 3rd ed.; Pearson: Boston, MA, 2014.

26. Gates, B.; Chambers, R. From aspiration to action: What will it take to end malaria? http://endmalaria2040.org (accessed March 17, 2018).

27. Gillis, J. Short Answers to Hard Questions about Climate Change. The New York Times, November 28, 2015. https://www.nytimes.com/interactive/ 2015/11/28/science/what-is-climate-change.html (accessed March 17, 2018).

28. Torrice, M. Chem. Eng. News 2016, 26-29.

29. Casey, N. Hard Times in Venezuela Breed Malaria as Desperate Flock to Mines. The New York Times, August 15, 2016; p A1.

30. Burgess, S. J.; Kelly, J. X.; Shomloo, S.; Wittlin, S.; Brun, R.; Liebmann, K.; Peyton, D. H. J. Med. Chem. 2010, 53, 6477-6489.

31. Waldbusser, G. G.; Hales, B.; Langdon, C. J.; Haley, B. A.; Schrader, P.; Brunner, E. L.; Gray, M. W.; Miller, C. A.; Gimenez, I. Nat. Clim. Change 2015, 5, 273-280.

32. Zhang, Y.; Griffin, A.; Rahman, M.; Camper, A.; Baribeau, H.; Edwards, M. Environ. Sci. Technol. 2009, 43, 1890-1895.

33. Deliberative Democracy. https://www.pdx.edu/stem/deliberativedemocracy (accessed March 17, 2018). 